\title{
Giant Sigmoid Colon Diverticulum
}

\author{
José Salazar-lbargüen Ricardo O. Escárcega Gonzalo Pérez Chávez \\ Hospital de Especialidades, Centro Medico Nacional Manuel Ávila Camacho, Instituto Mexicano del Seguro Social, \\ Puebla, México
}

A 73 -year-old female was admitted to our centre because of signs and symptoms that suggested bowel obstruction and that persisted for $48 \mathrm{~h}$. Her past medical history was uneventful except for multiple blood transfusions because of chronic iron deficiency anaemia. The abdominal X-ray (fig. 1) taken at the time of first evaluation revealed an air-fluid level. The patient underwent an exploratory laparotomy through a supra- and infraumbilical midline incision. During surgery, a giant sigmoid colon diverticulum was found incidentally which

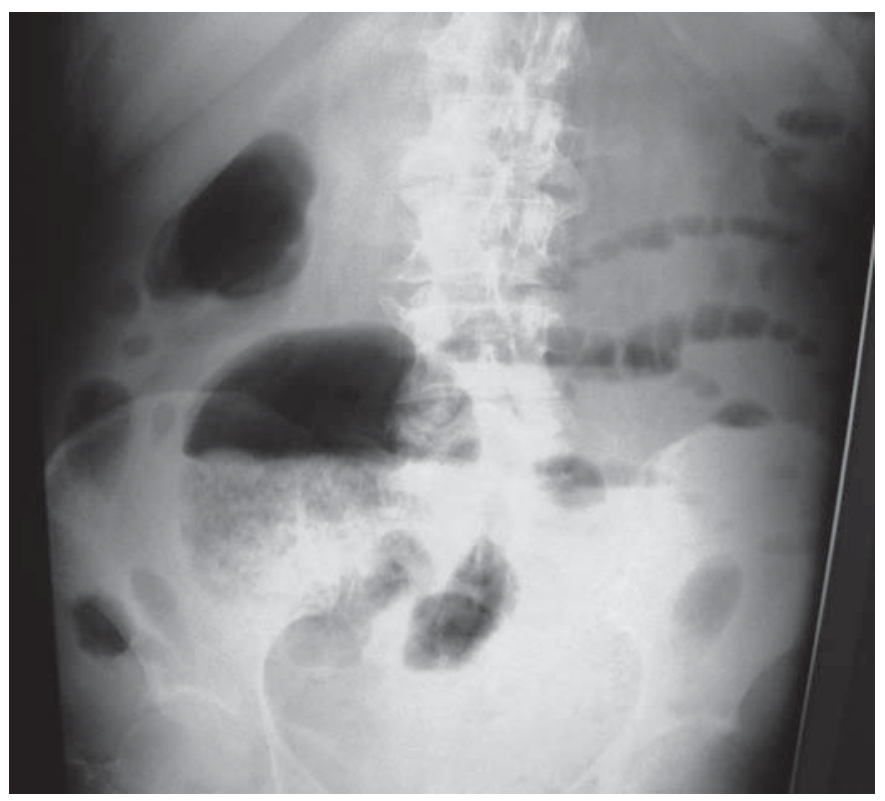

Fig. 1. Abdominal X-ray revealing air-fluid levels, suggesting bowel obstruction.

\section{KARGER}

Fax +41613061234 E-Mail karger@karger.ch www.karger.com (c) 2007 S. Karger AG, Basel

0253-4886/07/0241-0017\$23.50/0

Accessible online at:

www.karger.com/dsu was approximately $15 \mathrm{~cm}$ long. The rest of the bowel exploration did not reveal any abnormalities. Diverticulectomy was deferred for proper bowel preparation. During diverticulectomy, a giant sigmoid colon diverticulum was localized (fig. 2) and after careful dissection was excised. In addition to sigmoid colon resection, primary bowel anastomosis was performed. The surgical specimen measured $15 \mathrm{~cm}$ in length (fig. 3) and was confirmed by our pathology department as a giant sigmoid colon diverticulum.

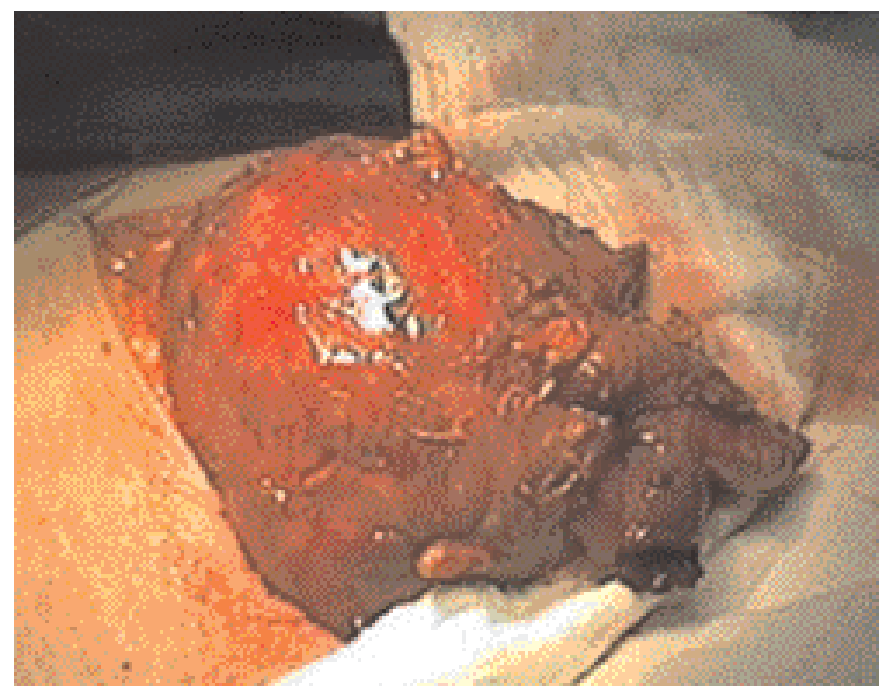

Fig. 2. Giant colonic diverticulum found during surgery.

Dr. Gonzalo Pérez Cháve

11 Norte No. 4407 Colonia Santa María

72080 Puebla (México)

Tel. +52 22222020 94, Fax +52 2222205631

E-Mail gonzalomd@latinmail.com 


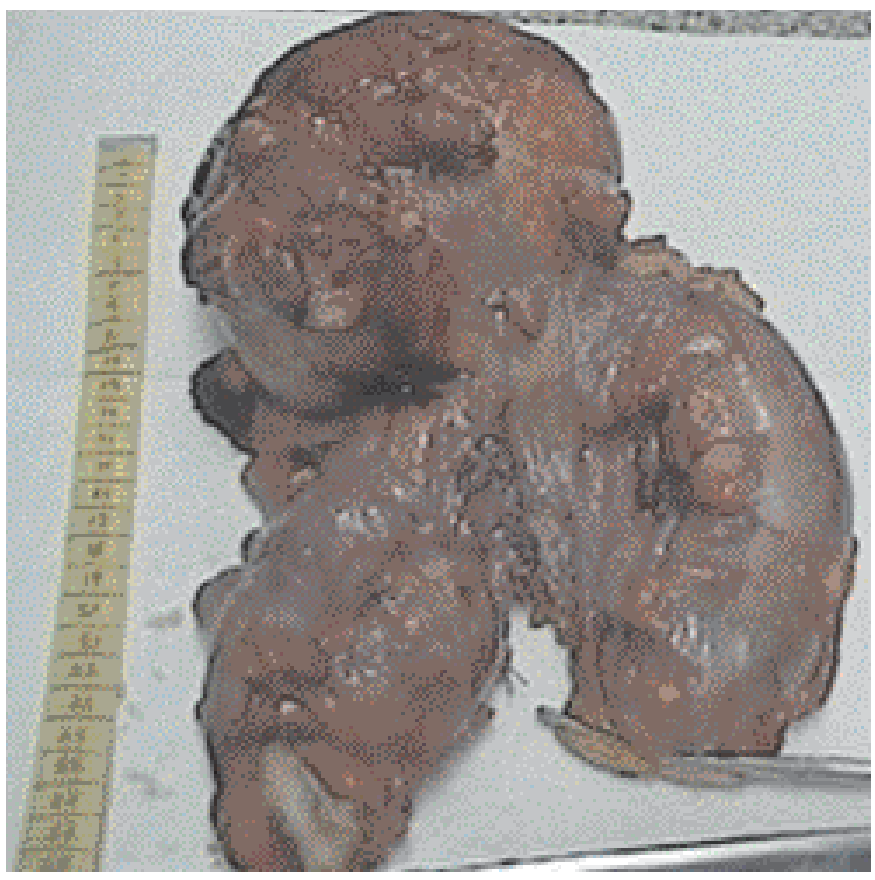

Fig. 3. Surgical specimen measuring $15 \mathrm{~cm}$ in length.
A giant colonic diverticulum is a rare complication of diverticular disease, with less than 150 cases reported in the English literature. The clinical presentation ranges from asymptomatic to an acute abdomen. In most cases, a giant colonic diverticulum is found in the sigmoid colon [1].

Sigmoid resection with primary anastomosis is the preferred treatment, although patients presenting with complications typically should be treated with Hartmann's procedure for free perforation or percutaneous drainage for a localized abscess. Because of the high risk of complications, segmental resection of the colon involved is recommended for diverticula found incidentally [2]

References Ciardiello K: Ruptured giant colonic diverticulum. Am Surg 2005;71:1073-1074.

2 Custer TJ, Blevins DV, Vara TM: Giant colonic diverticulum: a rare manifestation of a common disease. J Gastrointest Surg 1999;3: 543-548. 